\title{
Realizing Green Phosphorescent Light-Emitting Materials from Rhenium(I) Pyrazolato Diimine Complexes
}

\author{
Sudhir Ranjan, Shen-Yi Lin, Kuo-Chu Hwang, ${ }^{*}$ Yun Chi, ${ }^{*}$ Wei-Li Ching, and Chao-Shiuan Liu \\ Department of Chemistry, National Tsing Hua University, Hsinchu 30013, Taiwan, \\ Republic of China
}

Yu-Tai Tao* and Chin-Hsiung Chien

Institute of Chemistry, Academia Sinica, Taipei 11529, Taiwan, Republic of China

Shie-Ming Peng and Gene-Hsiang Lee

Department of Chemistry and Instrumentation Center, National Taiwan University, Taipei 10764, Taiwan, Republic of China

Received August 1, 2002

\begin{abstract}
Two neutral pyrazolato diimine rhenium(I) carbonyl complexes with formula $\left[\operatorname{Re}(\mathrm{CO})_{3}(\mathrm{~N}-\mathrm{N})(\mathrm{btpz})\right]$ where $\mathrm{N}-\mathrm{N}=$ 2,2'-bipyridine (1) and 1,10-phenanathroline (2), and btpz $=3,5$-bis(trifluoromethyl) pyrazolate, were synthesized and characterized by elemental analysis, routine spectroscopic methods, and single-crystal X-ray diffraction study. Ground and excited state properties of these complexes were investigated by steady-state and time-resolved spectroscopies. Complexes 1 and 2 show photoluminescent emission in both solution and solid-state at room temperature, arising from metal to ligand charge-transfer (MLCT) transition with strong overlapping of intraligand $\pi \rightarrow \pi^{*}$ transitions. The long-lived excited state lifetimes of complexes 1 and 2 , which are on the order of microseconds, indicate the presence of phosphorescent emission. As these complexes hold the potential to serve as phosphors for organic light-emitting diodes (OLEDs), their electroluminescent performances were evaluated by employing them as dopants of various electron transport layer (ETL) or hole transport layer (HTL) hosts. For complex 1 , a green electrophosphorescence emission centered at $\lambda_{\max }=530 \mathrm{~nm}$ was observed at low turn-on voltage ( $\sim 6 \mathrm{~V}$ ) with luminous power efficiency of $0.72 \mathrm{Im} / \mathrm{W}$, external quantum efficiency of $0.82 \%$, and luminance of $2300 \mathrm{~cd} / \mathrm{m}^{2}$ at a current density of $100 \mathrm{~mA} / \mathrm{cm}^{2}$.
\end{abstract}

Since the pioneering work done by Tang and VanSlyke, ${ }^{1}$ who first used tris(8-hydroxyquinoline) aluminum $\left(\mathrm{Alq}_{3}\right)$ to fabricate organic light-emitting diodes (OLEDs), the design and synthesis of other metal-containing luminophores has become the aim of many current research endeavors. Recently, this research has been extended to the $\mathrm{Be}(\mathrm{II})^{2}{ }^{2}$ $\mathrm{B}(\mathrm{III}),{ }^{3} \mathrm{Al}(\mathrm{III}),{ }^{4} \mathrm{Cu}(\mathrm{I}),{ }^{5} \mathrm{Zn}(\mathrm{II}),{ }^{6}$ and $\mathrm{Ru}(\mathrm{II}){ }^{7}$ metal-chelate

* Authors to whom correspondence should be addressed. E-mail: ychi@ mx.nthu.edu.tw (Y.C). Fax: (886) 3 572-0864 (Y.C.); kchwang@ mx.nthu.edu.tw (K.-C.H.); ytt@chem.sinica.edu.tw (Y.-T.T.).

(1) Tang, C. W.; VanSlyke, S. A. Appl. Phys. Lett. 1987, 51, 913.

(2) (a) Hamada, Y.; Sano, T.; Fujita, M.; Fujii, T.; Nishio, Y.; Shibata, K. Chem. Lett. 1993, 905. (b) Hu, N.-X.; Esteghamatian, M.; Xie, S.; Popovic, Z.; Hor, A.-M.; Ong, B.; Wang, S. Adv. Mater. 1999, 11, 1460. (c) Li, Y.; Liu, Y.; Bu, W.; Lu, D.; Wu, Y; Wang, Y. Chem. Mater. 2000, 12, 2672.

1248 Inorganic Chemistry, Vol. 42, No. 4, 2003 complexes and even the rare-earth complexes containing $\mathrm{Tb}$ $(\mathrm{III})^{8}$ and $\mathrm{Eu}(\mathrm{III})^{9}$ metal ions; most of them have shown bright emissions covering a broad spectrum of all visible wavelengths. In the meantime, metal-chelate compounds involving 5d-transition metal elements have also received

(3) (a) Wu, Q.; Esteghamatian, M.; Hu, N.-X.; Popovic, Z.; Enright, G.; Breeze, S. R.; Wang, S.; Angew. Chem., Int. Ed. 1999, 38, 985. (b) Anderson, S.; Weaver, M. S.; Hudson, A. J. Synth. Met. 2000, 111112, 459. (c) Li, Y.; Liu, Y.; Bu, W.; Gao, J.; Wang, Y. Chem. Commun. 2000, 1551. (d) Liu, S.-F.; Wu, Q.; Schmider, H. L.; Aziz, H.; Hu, N.-X.; Popovic, Z.; Wang, S. J. Am. Chem. Soc. 2000, 122, 3671.

(4) (a) Tang, C. W.; vanSlyke; S. A.; Chen, C. H. J. Appl. Phys. 1989 , 65, 3611. (b) Shi, J. M.; Tang, C. W. Appl. Phys. Lett. 1997, 70, 1665. (c) Kido, J.; Iizumi, Y. Appl. Phys. Lett. 1998, 73, 2721.

(5) Ma, Y.-G.; Chan, W.-H.; Zhou, X.-M.; Che, C.-M. New J. Chem. 1999 263.

10.1021/ic0259181 CCC: $\$ 25.00$ C 2003 American Chemical Society Published on Web 01/17/2003 
increased attention, simply because this class of compounds provides good phosphorescent emitters, where strong spinorbit coupling would enhance the singlet-triplet mixing, affording a fairly long-lived excited state with high emission quantum efficiencies. Theoretically, the devices prepared using these phosphorescent heavy metal complexes would display efficiency 3-4 times better than that of devices based on fluorescent materials.

This high expectation on the enhanced internal quantum efficiency has initiated more investigations on the metal complexes involving iridium, ${ }^{10}$ osmium, ${ }^{11}$ and platinum, ${ }^{12}$ from which many light-emitting devices have been successfully fabricated. With the aim of further extending the scope, efforts have now been focused on the $\operatorname{Re}(\mathrm{I})$ analogues, ${ }^{13}$ of which the $\mathrm{d}^{6}$ electronic configuration is identical to that of the corresponding Os(II) and Ir(III) systems. Thus, they are anticipated to show electroluminescence in the solid-state, a mandatory feature for real-world OLED applications.

Among the various $\operatorname{Re}(\mathrm{I})$ complexes reported in the literature ${ }^{14}$ one particular example is the chelate complex fac- $\left[\operatorname{Re}(\mathrm{CO})_{3}(\mathrm{~N}-\mathrm{N})(\mathrm{X})\right]$, where $\mathrm{N}-\mathrm{N}=$ diimine and $\mathrm{X}=$ halides, which is known to exhibit phosphorescent emission, and its photophysical properties can be tailored by varying the nature of the light-emitting ancillary ligands. ${ }^{15}$ The

(6) (a) Hamada, Y.; Sano, T.; Fujita, M.; Fujii, T.; Nishio, Y.; Shibata, K. Jpn. J. Appl. Phys. 1993, 32, L511. (b) Okada, K.; Wang, Y.-F.; Chen, T.-M.; Nakaya, T. Thin Solid Films 1999, 346, 69. (c) Ma, Y.; Lai, T.; Wu, Y. Adv. Mater. 2000, 12, 433. (d) Yu, G.; Liu, Y; Song, Y.; Wu, X.; Zhu, D. Synth. Met. 2001, 117, 211. (e) Wu, Q.; Lavigne, J. A.; Tao, Y.; D'Iorio, M.; Wang, S. Inorg. Chem. 2000, 39, 5248.

(7) (a) Lee, J.-K.; Yoo, D. S.; Handy, E. S.; Rubner M. F. Appl. Phys. Lett. 1996, 69,1686. (b) Gao, F. G.; Bard, A. J. J. Am. Chem. Soc. 2000, 122, 7426. (c) Rudmann, H.; Rubner, M. F. J. Appl. Phys. 2001 90, 4338.

(8) (a) Kido, J.; Nagai, K.; Ohashi, Y. Chem. Lett. 1990, 657. (b) Gao, X. C.; Cao, H.; Huang, C.; Li, B. Appl. Phys. Lett. 1998, 72, 2217. (c) Wang, J.; Wang, R.; Yang, J.; Zheng, Z.; Carducci, M. D.; Cayou, T.; Peyghambarian, N.; Jabbour, G. E. J. Am. Chem. Soc. 2001, 123, 6179.

(9) (a) Kido, J.; Hayase, H.; Hongawa, K.; Nagai, K.; Okuyama, K. Appl. Phys. Lett. 1994, 65, 2124. (b) Hu, W.; Matsumura, M.; Wang, M.; Jin, L. Appl. Phys. Lett. 2000, 77, 4271. (c) Robinson, M. R.; O'Regan, M. B.; Bazan, G. C. Chem. Commun. 2000, 1645. (d) Hong, Z. R.; Liang, C. J.; Li, R. G.; Li, W. L.; Zhao, D.; Fan, D.; Wang, D. Y.; Chu, B.; Zang, F. X.; Hong, L.-S.; Lee, S.-T. Adv. Mater. 2001, 13, 1241 .

(10) (a) Baldo, M. A.; O’Brien, D. F.; You, Y.; Shoustikov, A.; Sibley, S.; Thompson, M. E.; Forrest, S. R. Nature 1998, 395, 151. (b) Tsutsui, T.; Yang, M.-J.; Yahiro, M.; Nakamura, K.; Watanabe, T.; Tsuji, T.; Fukuda, Y.; Wakimoto, T.; Miyaguchi, S. Jpn. J. Appl. Phys. 1999, 38, L1502. (c) Baldo, M. A.; Lamansky, S.; Burrows, P. E.; Thompson, M. E.; Forrest, S. R. Appl. Phys. Lett. 1999, 75, 4. (d) Adachi, C.; Baldo, M. A.; Forrest, S. R.; Thompson, M. E. Appl. Phys. Lett. 2000, 77, 904. (e) Ostrowski, J. C.; Robinson, M. R.; Heeger, A. J.; Bazan, G. C. Chem. Commun. 2002, 784.

(11) (a) Ma. Y.; Zhang, H.; Shen, J; Che, C.-M. Synth. Met. 1998, 94, 245. (b) Bernhard, S.; Gao, X.; Malliaras, G. G.; Abruna, H. D. Adv. Mater. 2002, 14, 433. (c) Jiang, X.; Jen, A. K.-Y.; Carlson, B.; Dalton, L. R. Appl. Phys. Lett. 2002, 80, 713.

(12) (a) Kwong, R. C.; Sibley, S.; Dubovoy, T.; Baldo, M.; Forrest, S. R.; Thompson, M. E. Chem. Mater. 1999, 11, 3709. (b) Chan, S. C.; Chan, M. C. W.; Wang, Y.; Che, C.-M.; Cheung, K. K.; Zhu, N. Chem. Eur. J. 2001, 7, 4180. (c) Lu, W.; Mi, B.-X.; Chan, C. W. Hui, Z.; Zhu, N.; Lee, S.-T.; Che, C.-M. Chem. Commun. 2002, 206.

(13) (a) Gong, X.; Ng, P. K.; Chan, W. K. Adv. Mater. 1998, 10, 1337. (b) Li, Y.; Wang, Y.; Zhang, Y.; Wu, Y.; Shen, J. Synth. Met. 1999, 99, 257. (c) Chan, W. K.; Ng, P. K.; Gong, X.; Hou, S. Appl. Phys. Lett. 1999, 75, 3920. (d) Li, Y.; Liu, Y; Guo, J.; Wu, F.; Tian, W.; Li, B.; Wang, Y. Synth. Met. 2001, 118, 175. (e) Wang, K.; Huang, L.; Gao. L.; Jin, L.; Huang, C. Inorg. Chem. 2002, 41, 3353.
Scheme 1

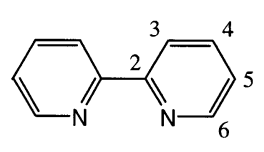

bpy

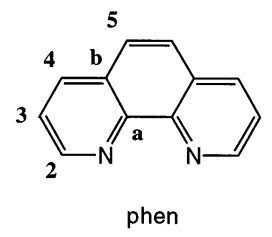

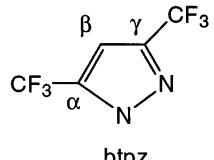

btpz electronic states responsible for luminescence in these Re(I) complexes were then assigned to a mixture of a metalto-ligand charge-transfer (MLCT) state and an intraligand charge-transfer state. ${ }^{16}$

In this article, we wish to report the synthesis and characterization of two related $\operatorname{Re}(\mathrm{I})$ complexes, $\left[\operatorname{Re}(\mathrm{CO})_{3^{-}}\right.$ $(\mathrm{N}-\mathrm{N})(\mathrm{btpz})]$, where $\mathrm{N}-\mathrm{N}=2,2^{\prime}$-bipyridine (bpy) (1) and 1,10-phenanathroline (phen) (2), and btpz $=3,5$-bis(trifluoromethyl) pyrazolate. It is believed that the fluorinated substituents on the btpz ligand will reduce the vibrational relaxation of excited states and increase the volatility that aids future device processing. In addition, the electroluminescence (EL) properties of complexes $\mathbf{1}$ and $\mathbf{2}$ have been explored, and a number of strategies have been employed for the fabrication of the respective OLEDs.

\section{Experimental Section}

General Information and Materials. All synthetic manipulations were performed under $\mathrm{N}_{2}$ atmosphere using standard Schlenk technique. All solvents were dried before use, using the appropriate drying reagents. $\operatorname{Re}_{2}(\mathrm{CO})_{10}$ was purchased from Strem Chemicals, and the diimine ligands 2,2'-bipyridine and 1,10-phenanthroline (Aldrich) were used as received. Rhenium carbonyl complexes [Re$\left.(\mathrm{CO})_{5} \mathrm{Br}\right],{ }^{17}\left[\mathrm{Re}(\mathrm{CO})_{3}(\mathrm{bpy}) \mathrm{Br}\right],{ }^{18}$ and $\left[\mathrm{Re}(\mathrm{CO})_{3}(\right.$ phen $\left.) \mathrm{Br}\right]{ }^{19}$ were prepared according to literature methods. For the spectroscopic identification, the labeling of the bpy, phen, and btpz ligand is given in Scheme 1.

Mass spectra were obtained on a Thermo Quest FINNIGAN MAT 95-XL instrument operating in electron impact (EI) mode. ${ }^{1} \mathrm{H},{ }^{13} \mathrm{C}$, and ${ }^{19} \mathrm{~F}$ NMR spectra were recorded on a Varian Mercury400 or an Inova-500 instrument; chemical shifts are quoted with respect to internal standard tetramethylsilane for ${ }^{1} \mathrm{H}$ and ${ }^{13} \mathrm{C} \mathrm{NMR}$ and $\mathrm{CFCl}_{3}$ for ${ }^{19} \mathrm{~F}$ NMR data. Elemental analyses were carried out at the NSC Regional Instrumentation Center at National Cheng Kung University, Tainan, Taiwan. IR spectra were recorded on a

(14) (a) Luong, J. C.; Nadjo, L.; Wrighton, M. S. J. Am. Chem. Soc. 1978, 100, 5790. (b) Lees, A. J. Chem. Rev. 1987, 87, 711. (c) Kalyanasundaram, K. Photochemistry of Polypyridine and Porphyrin Complexes; Academic Press: London, 1992. (d) Schanze, K. S.; MacQueen, D. B.; Perkins, T. A.; Cabana, L. A. Coord. Chem. Rev. 1993, 93, 63. (e) Vogler, A.; Kunkeley, H. Coord. Chem. Rev. 2000, 200-202, 991. (f) Sun, S.-S.; Lees, A. J. J. Am. Chem. Soc. 2000, $122,8956$.

(15) (a) Casper, J. V.; Meyer, T. J. J. Phys. Chem. 1983, 87, 952. (b) Wang, Y.; Hauser, B. T.; Rooney, M. M.; Burton, R. D.; Schanze, K. S. J. Am. Chem. Soc. 1993, 115, 5675. (c) Guerrero, J.; Piro, O. E.; Wolkan, E.; Feliz, M. R.; Ferraudi, G.; Moya, S. A. Organometallics 2001, 20, 2842. (d) Lo, K. K.-W.; Hui, W.-K.; Ng, D. C.-M.; Cheung, K.K. Inorg. Chem. 2002, 41, 40.

(16) (a) Giordano, P. G.; Fredericks, S. M.; Wrighton, M. S.; Morse, D. L. J. Am. Chem. Soc. 1978, 100, 2257. (b) Fredericks, S. M.; Luong, J. C.; Wrighton, M. S. J. Am. Chem. Soc. 1979, 101, 7415. (c) Tapolsky, G.; Duesing, R; Meyer, T. J. Inorg. Chem. 1990, 29, 2285. (d) Leasure, R. M.; Sacksteder, L.; Nesselrodt, D.; Reitz, G. A.; Demas, J. N.; DeGraff, B. A. Inorg. Chem. 1991, 31, 3722.

(17) Abel, E. W.; Wilkinson, G. J. Chem. Soc. 1959, 1501.

(18) Horn, E.; Snow, M. R. Aust. J. Chem. 1980, 33, 2369.

(19) Luong, J. C.; Faltynek, R. A.; Wrighton, M. S. J. Am. Chem. Soc. 1980, 102, 7892 . 
Ranjan et al.

Perkin-Elmer 2000 FT-IR spectrometer. Electronic (UV-vis) absorption spectra were recorded on a Hitachi U-3300 spectrophotometer.

Emission spectra were recorded on a Jasco FP777 fluorescence spectrophotometer. The solid thin film samples were deposited on a Pyrex glass plate by spin-coater $(750 \mathrm{rpm})$ from a highly concentrated solution in $\mathrm{CH}_{2} \mathrm{Cl}_{2}(\sim 5 \mathrm{mg} / 0.5 \mathrm{~mL})$, which were dried in a vacuum oven for $6 \mathrm{~h}$. For preparation of the liquid samples, the solutions were deaerated by at least three successive freezepump-thaw cycles. The luminescence lifetimes were measured using a single photon counter (Edinburgh Analytical Instruments, Model $\mathrm{OB}$ 900) with a nanosecond $\mathrm{H}_{2}$ pulsed lamp as the light source, and the excited state lifetimes were measured from solid thin film samples. The luminescence quantum yields were measured by comparing fluorescence intensities (integrated areas) of a standard sample (quinine sulfate) and the unknown sample according to the following equation:

$$
\Phi_{\mathrm{u}} / \Phi_{\mathrm{r}}=F_{\mathrm{u}} \cdot A_{\mathrm{r}}\left(\eta_{\mathrm{u}}\right)^{2} / F_{\mathrm{r}} \cdot A_{\mathrm{u}}\left(\eta_{\mathrm{r}}\right)^{2}
$$

where $F_{\mathrm{u}}$ and $F_{\mathrm{r}}$ are the integrated fluorescence intensities of the unknown sample and the reference material, quinine sulfate, $A_{\mathrm{u}}$ and $A_{\mathrm{r}}$ are the absorbances of the unknown sample and quinine sulfate, at excitation wavelength of $366 \mathrm{~nm}$, and $\Phi_{\mathrm{r}}$ is the quantum yield of quinine sulfate and is taken as $0.53 .{ }^{20}$ The $\eta_{\mathrm{u}}$ and $\eta_{\mathrm{r}}$ are the refractive indices of the solvents.

Cyclic voltammetry measurements were conducted on a voltammetric analyzer (CH Instruments, Model 830) with a polished $\mathrm{Pt}$ plate as the working electrode, Pt mesh as the counter electrode, and a commercially available saturated calomel electrode (SCE) as the reference electrode, at a scan rate of $0.1 \mathrm{~V} / \mathrm{s}$. The voltammograms were recorded using $\mathrm{CH}_{2} \mathrm{Cl}_{2}$ and $\mathrm{CH}_{3} \mathrm{CN}$ sample solutions with $\sim 10^{-3} \mathrm{M}$ of $\mathbf{1}$ and $\mathbf{2}$, and $0.1 \mathrm{M}$ of $n$-tetrabutylammonium hexafluorophosphate (TBAH) as the supporting electrolyte. Prior to each electrochemical measurement, the solution was purged with argon for $\sim 10-15$ min to remove the dissolved $\mathrm{O}_{2}$ gas.

OLED Device Fabrication. The charge-transporting materials NPB (4,4'-bis[ $N$-(1-naphthyl)- $N$-phenylamino]biphenyl), CBP (4,4'dicarbazolyl-1,1'-biphenyl), TPBI [2,2',2"-(1,3,5-benzenetriyl)tris(1-phenyl-1H-benzimidazole)], and Alq [tris(8-hydroxyquinoline) aluminum] were synthesized according to literature procedures and sublimed at least twice through a temperature-gradient sublimation system. Prepatterned ITO substrates with a resistivity $<30 \Omega / \square$ and an effective individual device area of $3.14 \mathrm{~mm}^{2}$ were cleaned by sonication in detergent solution, water, and ethanol sequentially. After being blown dry with nitrogen, the ITO substrates were treated with oxygen plasma for $1 \mathrm{~min}$ before being loaded into the vacuum chamber. The various organic layers were deposited sequentially at a rate of $\sim 0.1-0.3 \mathrm{~nm} / \mathrm{s}$ under a pressure of $\sim 2 \times 10^{-5}$ Torr in an Ulvac Cryogenic deposition system. An alloy of magnesium and silver (ca. 10:1 by weight, $50 \mathrm{~nm}$ ) was deposited as the cathode, which was capped with $100 \mathrm{~nm}$ of silver. The current-voltageluminance was measured in ambient with a Keithley 2400 Source meter and a Newport 1835C Optical meter equipped with 818ST silicon photodiode.

Synthesis of $\left[\operatorname{Re}(\mathbf{C O})_{\mathbf{3}}(\mathbf{b p y})(\mathbf{b t p z})\right](\mathbf{1})$. Sodium hydride $(0.088$ $\mathrm{g}, 3.69 \mathrm{mmol})$ in THF $(15 \mathrm{~mL})$ was taken in a $50 \mathrm{~mL}$ round-bottom flask. To this was slowly added $0.58 \mathrm{~g}$ of (btpz) $\mathrm{H}(2.85 \mathrm{mmol})$ dissolved in $10 \mathrm{~mL}$ of THF until the evolution of hydrogen gas had stopped. After $30 \mathrm{~min}$, excess sodium hydride was filtered,

(20) Adam, M. J.; Highfield, J. G.; Kirkbright, G. F. Anal. Chem. 1977, 49, 1850. and solvent was evaporated. The sodium salt of btpz ligand was redissolved in toluene and poured into a suspension of $\left[\operatorname{Re}(\mathrm{CO})_{3^{-}}\right.$ (bpy)Br] $(0.9 \mathrm{~g}, 1.8 \mathrm{mmol})$ in toluene solvent $(30 \mathrm{~mL})$. The resulting reaction mixture was allowed to reflux for $6 \mathrm{~h}$. After the solution was cooled to room temperature, solvent was removed in vacuo. Excess (btpz)Na was removed after washing with hexane. The crude solid was dissolved in $\mathrm{CH}_{2} \mathrm{Cl}_{2}(250 \mathrm{~mL})$, and the mixture was filtered through Celite to remove insoluble sodium bromide. The filtrate was evaporated to dryness. The yellow solid material was then purified by sublimation $\left(150{ }^{\circ} \mathrm{C} / 400 \mathrm{mTorr}\right)$, giving $0.95 \mathrm{~g}$ of $\left[\operatorname{Re}(\mathrm{CO})_{3}(\mathrm{bpy})(\mathrm{btpz})\right](\mathbf{1}, 1.51 \mathrm{mmol}, 85 \%)$.

Spectral data of 1: MS (EI, $70 \mathrm{eV}, m / e^{+}, \mathrm{M}=\left[\operatorname{Re}(\mathrm{CO})_{3}(\mathrm{bpy})-\right.$ (btpz)]), observed (actual) \{relative abundance\} [assignment]: 630 (630) $\{26.1\}[\mathrm{M}], 602$ (602) $\{23.8\}[\mathrm{M}-\mathrm{CO}], 574$ (574) $\{7.6\}$ $[\mathrm{M}-2 \mathrm{CO}], 546(546)\{100\}[\mathrm{M}-3 \mathrm{CO}] .{ }^{1} \mathrm{H}$ NMR $(500 \mathrm{MHz}$, $\left.\mathrm{CD}_{3} \mathrm{CN}\right): \delta 9.0\left(\mathrm{~d}, 2 \mathrm{H},{ }^{3} J_{\mathrm{HH}}=5.0 \mathrm{~Hz}, \mathrm{H}^{6}\right), 8.36\left(\mathrm{~d}, 2 \mathrm{H},{ }^{3} J_{\mathrm{HH}}=\right.$ $\left.8.5 \mathrm{~Hz}, \mathrm{H}^{3}\right), 8.16\left(\mathrm{td}, 2 \mathrm{H},{ }^{3} J_{\mathrm{HH}}=7.9 \mathrm{~Hz},{ }^{4} J_{\mathrm{HH}}=1.0 \mathrm{~Hz}, \mathrm{H}^{4}\right), 7.56$ $\left(\mathrm{td}, 2 \mathrm{H},{ }^{3} J_{\mathrm{HH}}=6.5 \mathrm{~Hz},{ }^{4} J_{\mathrm{HH}}=1.0 \mathrm{~Hz}, \mathrm{H}^{5}\right), 6.56\left(\mathrm{~s}, 1 \mathrm{H}, \mathrm{H}^{\beta}\right) .{ }^{13} \mathrm{C}$ NMR (125 MHz, CD $\left.{ }_{3} \mathrm{CN}\right): \delta 198.0$ (CO), 193.9 (CO), 157.9 (2C, 2), $154.5(2 \mathrm{C}, 6), 142.5$ (q, $\left.1 \mathrm{C},{ }^{2} J_{\mathrm{CF}}=35.6 \mathrm{~Hz}, \alpha\right), 142.3(\mathrm{q}, 1 \mathrm{C}$, $\left.{ }^{2} J_{\mathrm{CF}}=36.6 \mathrm{~Hz}, \gamma\right), 141.0(2 \mathrm{C}, 3), 128.0(2 \mathrm{C}, 4), 124.2(2 \mathrm{C}, 5)$, $122.8\left(\mathrm{q}, 1 \mathrm{C},{ }^{1} J_{\mathrm{CF}}=267.7 \mathrm{~Hz}, \mathrm{CF}_{3}\right), 122.7\left(\mathrm{q}, 1 \mathrm{C},{ }^{1} J_{\mathrm{CF}}=267.7\right.$ $\left.\mathrm{Hz}, \mathrm{CF}_{3}\right), 104.8(1 \mathrm{C}, \beta) .{ }^{19} \mathrm{~F}$ NMR $\left(470 \mathrm{MHz}, \mathrm{CD}_{3} \mathrm{CN}\right): \delta-57.2$ $\left(3 \mathrm{~F}, \mathrm{CF}_{3}\right),-61.4\left(3 \mathrm{~F}, \mathrm{CF}_{3}\right) . \mathrm{IR}\left(\mathrm{CH}_{2} \mathrm{Cl}_{2}\right): v(\mathrm{CO}) 2028(\mathrm{~s}), 1923$ (br) $\mathrm{cm}^{-1}$. Anal. Calcd for $\mathrm{C}_{18} \mathrm{H}_{9} \mathrm{~F}_{6} \mathrm{~N}_{4} \mathrm{O}_{3} \mathrm{Re}$ : C 34.34, $\mathrm{H} 1.44, \mathrm{~N}$ 8.90. Found: C 34.32, H 1.79, N 8.81\%.

Synthesis of $\left[\operatorname{Re}(\mathrm{CO})_{3}(\right.$ phen $\left.)(b t p z)\right](2)$. The synthetic procedure is essentially the same as that for $\mathbf{1}$, except 1,10-phenanthroline was taken to replace the $2,2^{\prime}$-bipyridine ligand. The yellow solid material was then purified by sublimation $\left(165^{\circ} \mathrm{C} / 400\right.$ mTorr $)$, giving $1.0 \mathrm{~g}$ of $\left[\operatorname{Re}(\mathrm{CO})_{3}(\mathrm{phen})(\mathrm{btpz})\right](2,1.53 \mathrm{mmol}, 90 \%)$. Single crystals suitable for $\mathrm{X}$-ray diffraction analysis were recrystallized from a saturated $\mathrm{CH}_{2} \mathrm{Cl}_{2}$ solution at room temperature.

Spectral data of 2: MS (EI, $70 \mathrm{eV}, m / e^{+}, \mathrm{M}=\left[\operatorname{Re}(\mathrm{CO})_{3}(\mathrm{phen})-\right.$ (btpz)]), observed (actual) \{relative abundance [assignment]: 654 (654) $\{57.8\}[\mathrm{M}], 626$ (626) $\{61.4\}[\mathrm{M}-\mathrm{CO}], 598$ (598) $\{5.5\}$ $[\mathrm{M}-2 \mathrm{CO}], 570(570)\{100\}[\mathrm{M}-3 \mathrm{CO}] .{ }^{1} \mathrm{H} \mathrm{NMR}(500 \mathrm{MHz}$, $\left.\mathrm{CD}_{3} \mathrm{CN}\right): \delta 9.39\left(\mathrm{dd}, 2 \mathrm{H},{ }^{3} J_{\mathrm{HH}}=5.0 \mathrm{~Hz},{ }^{4} J_{\mathrm{HH}}=1.5 \mathrm{~Hz}, \mathrm{H}^{2}\right), 8.69$ $\left(\mathrm{dd}, 2 \mathrm{H},{ }^{3} J_{\mathrm{HH}}=8.5 \mathrm{~Hz},{ }^{4} J_{\mathrm{HH}}=1.5 \mathrm{~Hz}, \mathrm{H}^{4}\right), 8.07\left(\mathrm{~s}, 2 \mathrm{H}, \mathrm{H}^{5}\right), 7.89$ $\left(\mathrm{dd}, 2 \mathrm{H},{ }^{3} J_{\mathrm{HH}}=8.0 \mathrm{~Hz},{ }^{4} J_{\mathrm{HH}}=5.0 \mathrm{~Hz}, \mathrm{H}^{3}\right), 6.45\left(\mathrm{~s}, 1 \mathrm{H}, \mathrm{H}^{\beta}\right) .{ }^{13} \mathrm{C}$ NMR (125 MHz, CD ${ }_{3} \mathrm{CN}$ ): $\delta 197.9$ (CO), 193.9 (CO), 154.9 (2C, 2), $148.7(2 \mathrm{C}, \mathbf{a}), 142.4\left(\mathrm{q}, 1 \mathrm{C},{ }^{2} J_{\mathrm{CF}}=35.9 \mathrm{~Hz}, \alpha\right), 142.2(\mathrm{q}, 1 \mathrm{C}$, $\left.{ }^{2} J_{\mathrm{CF}}=36.2 \mathrm{~Hz}, \gamma\right), 140.1(2 \mathrm{C}, 4), 131.4(2 \mathrm{C}, \mathbf{b}), 128.4(2 \mathrm{C}, \mathbf{5})$, $126.8(2 \mathrm{C}, 3), 122.7\left(\mathrm{q}, 1 \mathrm{C},{ }^{1} J_{\mathrm{CF}}=268.2 \mathrm{~Hz}, \mathrm{CF}_{3}\right), 122.6$ (q, 1C, $\left.{ }^{1} J_{\mathrm{CF}}=267.1 \mathrm{~Hz}, \mathrm{CF}_{3}\right), 104.6(1 \mathrm{C}, \beta) .{ }^{19} \mathrm{~F} \mathrm{NMR}\left(470 \mathrm{MHz}, \mathrm{CD}_{3^{-}}\right.$ $\mathrm{CN}): \delta-57.1\left(3 \mathrm{~F}, \mathrm{CF}_{3}\right),-61.6\left(3 \mathrm{~F}, \mathrm{CF}_{3}\right) . \mathrm{IR}\left(\mathrm{CH}_{2} \mathrm{Cl}_{2}\right): v(\mathrm{CO})$ 2029 (s), 1923 (br) $\mathrm{cm}^{-1}$. Anal. Calcd for $\mathrm{C}_{20} \mathrm{H}_{9} \mathrm{~F}_{6} \mathrm{~N}_{4} \mathrm{O}_{3} \mathrm{Re}$ : C 36.76, H 1.39, N 8.57. Found: C 36.73, H 1.72, N 8.49\%.

X-ray Crystallography. X-ray diffraction data were measured on a Bruker SMART CCD diffractometer using $\lambda(\mathrm{Mo} \mathrm{K} \alpha)$ radiation, $0.7107 \AA$ at $295 \mathrm{~K}$. The data collection was executed using the SMART program. An empirical absorption was based on the symmetry-equivalent reflections and applied to the data using the SADABS program. The structure was solved using the SHELXTL-97 program. ${ }^{21}$ The crystallographic refinement parameters of $\mathbf{2}$ were summarized in Table 1, while the selected bond distances and angles were given in Table 2.

(21) (a) Sheldrick, G. M. SHELXTL, Version 5.10; Siemens Analytical X-ray Instruments Inc.: Madison, WI, 1998. (b) SMART and SAINT; Siemens Analytical X-ray Instruments Inc.: Madison, WI, 1995. (c) Sheldrick, G. M. SADABS; University of Göttingen: Göttingen, Germany, 1996. 
Table 1. X-ray Structural Data for Complex 2

$\begin{array}{ll}\mathrm{C}_{20} \mathrm{H}_{9} \mathrm{~F}_{6} \mathrm{~N}_{4} \mathrm{O}_{3} \mathrm{Re} \cdot 1 / 2 \mathrm{CH}_{2} \mathrm{Cl}_{2} & \text { mol wt }=695.98 \\ \text { cryst syst }=\text { triclinic, } P 1 & T=295(2) \mathrm{K} \\ a=10.8218(4) \AA & b=12.3617(4) \AA \\ c=18.9041(4) \AA & \alpha=103.64(1)^{\circ} \\ \beta=76.5780(7)^{\circ} & \gamma=78.9214(7)^{\circ} \\ V=2328.43(14) \AA^{3} & Z=4 \\ D_{\mathrm{c}}=1.985 \mathrm{~g} / \mathrm{cm}^{3} & F(000)=1324 \\ h, k, l \text { ranges } & -14 \text { to } 14,-16 \text { to } 16,-24 \text { to } 24 \\ \text { cryst size, } \mathrm{mm}^{3} & 0.20 \times 0.20 \times 0.12 \\ \mu(\mathrm{Mo} \mathrm{K} \alpha) \mathrm{mm}^{-1} & 5.412 \\ \text { transmission max, min } & 0.5189,0.3891 \\ \text { data/restraints/params } & 10685 / 4 / 630 \\ \mathrm{GOF} \text { on } F^{2} & 1.014 \\ \mathrm{R} 1, \text { wR2 with } I>2 \sigma(I) & 0.035,0.084 \\ D \text { map, max/min, e/ } \AA^{-3} & 1.089 /-0.991\end{array}$

Table 2. Selected Bond Distances $(\AA)$ and Angles (deg) for Complex 2

\begin{tabular}{cclc}
\hline $\operatorname{Re}(1)-\mathrm{C}(1)$ & $1.897(7)$ & $\operatorname{Re}(1)-\mathrm{C}(2)$ & $1.897(7)$ \\
$\operatorname{Re}(1)-\mathrm{C}(3)$ & $1.905(5)$ & $\operatorname{Re}(1)-\mathrm{N}(1)$ & $2.192(5)$ \\
$\operatorname{Re}(1)-\mathrm{N}(2)$ & $2.184(4)$ & $\operatorname{Re}(1)-\mathrm{N}(3)$ & $2.222(5)$ \\
$\mathrm{C}(1)-\operatorname{Re}(1)-\mathrm{C}(2)$ & $85.4(3)$ & $\mathrm{C}(1)-\operatorname{Re}(1)-\mathrm{C}(3)$ & $88.0(3)$ \\
$\mathrm{C}(1)-\operatorname{Re}(1)-\mathrm{N}(1)$ & $93.4(2)$ & $\mathrm{C}(1)-\operatorname{Re}(1)-\mathrm{N}(2)$ & $92.5(2)$ \\
$\mathrm{N}(3)-\operatorname{Re}(1)-\mathrm{C}(2)$ & $90.2(2)$ & $\mathrm{N}(3)-\operatorname{Re}(1)-\mathrm{C}(3)$ & $95.0(2)$ \\
$\mathrm{N}(3)-\operatorname{Re}(1)-\mathrm{N}(1)$ & $84.16(18)$ & $\mathrm{N}(3)-\operatorname{Re}(1)-\mathrm{N}(2)$ & $91.53(17)$ \\
$\mathrm{N}(1)-\operatorname{Re}(1)-\mathrm{N}(2)$ & $75.79(18)$ & $\mathrm{N}(2)-\operatorname{Re}(1)-\mathrm{C}(3)$ & $97.9(2)$ \\
$\mathrm{C}(2)-\operatorname{Re}(1)-\mathrm{C}(3)$ & $88.0(3)$ & $\mathrm{C}(2)-\operatorname{Re}(1)-\mathrm{N}(1)$ & $98.4(2)$ \\
$\mathrm{C}(2)-\operatorname{Re}(1)-\mathrm{N}(2)$ & $173.8(2)$ & $\mathrm{C}(3)-\operatorname{Re}(1)-\mathrm{N}(1)$ & $173.6(2)$ \\
$\mathrm{C}(1)-\operatorname{Re}(1)-\mathrm{N}(3)$ & $174.6(2)$ & &
\end{tabular}

Scheme 2

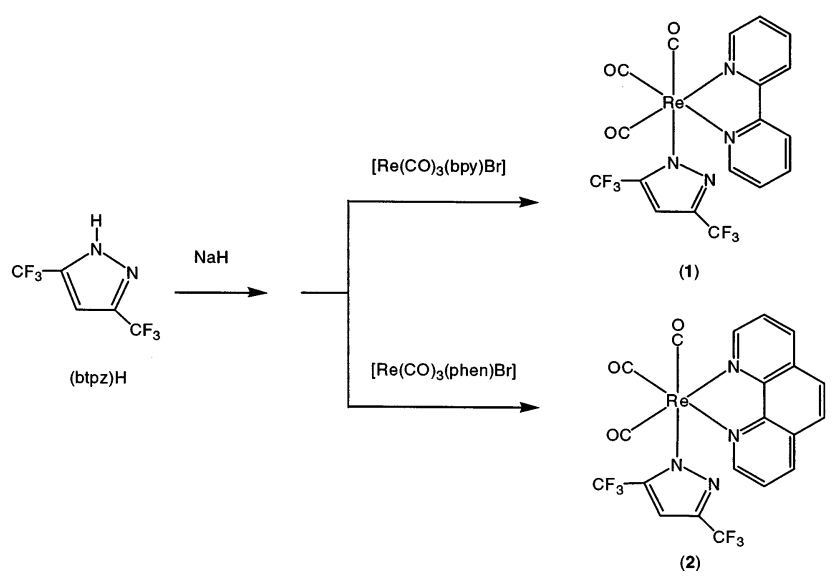

\section{Results and Discussion}

Synthesis and Characterization. As shown in Scheme 2, rhenium carbonyl complexes $\mathbf{1}$ and $\mathbf{2}$ were prepared in good yields by a direct reaction of $\left[\operatorname{Re}(\mathrm{CO})_{3}(\right.$ bpy $\left.) \mathrm{Br}\right]$ and $\left[\operatorname{Re}(\mathrm{CO})_{3}(\right.$ phen $\left.) \mathrm{Br}\right]$ with 1.6 equiv of the sodium salt of 3,5bis(trifluoromethyl) pyrazolate in toluene solution. After the reaction was completed, evaporation of solvent under vacuum and sublimation of the resulting solid residue at $\sim 150-165$ ${ }^{\circ} \mathrm{C}$ gave the anticipated complexes without any noticeable decomposition. Metal complexes $\mathbf{1}$ and $\mathbf{2}$ were found to be soluble in most of the common solvents, such as chloroform, acetone, THF, and acetonitrile, and were completely insoluble in nonpolar aromatic and aliphatic hydrocarbons such as toluene and hexane. Preparation of the corresponding 3,5dimethyl pyrazolate substituted derivatives was also carried out using the same synthetic strategy, but it gave severe decomposition during sublimation, which hampered our effort to broaden the scope of this study.

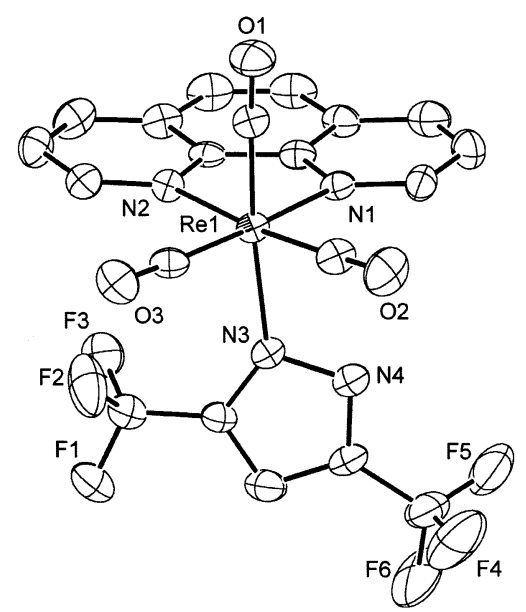

Figure 1. ORTEP diagram of complex 2 with thermal ellipsoids shown at $30 \%$ probability level.

The identities of these complexes were then confirmed by elemental analysis and EI mass, IR, and NMR spectrometry. The EI mass analysis shows the presence of the molecular ion $\mathrm{M}^{+}$at $\mathrm{m} / \mathrm{z}=630$ and 654 for complexes $\mathbf{1}$ and 2, respectively, and the corresponding daughter ions [M $-n \mathrm{CO}$ ], $n=1-3$, were also produced by the successive elimination of three carbonyl groups. The solution IR $v(\mathrm{CO})$ spectra of complexes $\mathbf{1}$ and $\mathbf{2}$ are essentially identical to each other, showing one sharp CO stretching absorption at 2028 $\mathrm{cm}^{-1}$ and a second, very broad stretching signal centered at $1923 \mathrm{~cm}^{-1}$. It is believed that the lower-frequency stretching band is derived from two poorly resolved $\mathrm{CO}$ stretching signals, and thus, this unique $v(\mathrm{CO})$ stretching pattern is consistent with the proposed facial configuration of $\mathrm{CO}$ ligands at the $\operatorname{Re}(\mathrm{CO})_{3}$ metal fragment. ${ }^{22}$ The ${ }^{1} \mathrm{H}$ and ${ }^{13} \mathrm{C}$ NMR spectral data were given in the Experimental Section. The spectral patterns due to the bpy and phen moieties are compatible to those reported in the literature. ${ }^{23}$ Moreover, the ${ }^{19} \mathrm{~F}$ NMR spectrum of complex 1 shows two fluorine signals at $\delta-57.2$ and -61.4 with equal intensities, while those of complex 2 appear at similar positions at $\delta-57.1$ and -61.6 , respectively. These observations are fully consistent with the presence of two magnetically nonequivalent $\mathrm{CF}_{3}$ groups for the btpz ligand, giving strong evidence for the direct coordination of the btpz ligand to the $\operatorname{Re}(\mathrm{I})$ metal center through only one of its nitrogen donor atoms. This unique structural characteristic was further revealed by the subsequent X-ray crystallography.

The single-crystal X-ray structure of $\mathbf{2}$ is shown in Figure 1 , while the bond distances and angles are summarized in Table 2. The $\operatorname{Re}(\mathrm{I})$ metal center adopts a slightly distorted octahedral geometry with coordination of three terminal carbonyl ligands arranged in a facial disposition and three additional nitrogen atoms, of which two were derived from phenanthroline and the third coming from the pyrazolate ligand. Thus, the local environment of the Re metal atom

(22) Giordano, P. J.; Wrighton, M. S. J. Am. Chem. Soc. 1979, 101, 2888.

(23) (a) Itokazu, M. K.; Polo, A. S.; de Faria, D. L. A.; Bignozzi, C. A.; Iha, N. Y. M. Inorg. Chim. Acta 2001, 313, 149. (b) Wolkan, E.; Torchia, G.; Tocho, J; Piro, O. E.; Juliarena, P.; Ruiz, G.; Feliz, M. R. J. Chem. Soc., Dalton Trans. 2002, 2194. 


\section{Ranjan et al.}

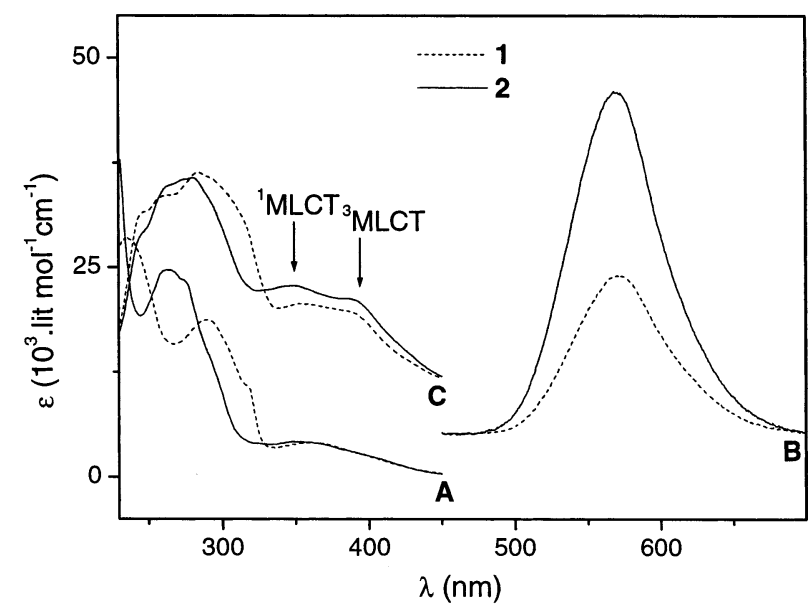

Figure 2. UV-vis spectra (A), emission spectra (B), and excitation spectra (C) of complexes $\mathbf{1}$ and $\mathbf{2}$ in $\mathrm{CH}_{2} \mathrm{Cl}_{2}$ solution, which are represented by dashed and solid lines, respectively.

most probably adopts a pseudo- $C_{3 v}$ symmetry, for which the unique $C_{3}$ rotational axis is passing through the center of two opposing triangular planes defined by three carbon atoms of the carbonyl groups and three nitrogen atoms of the phenanthroline and the pyrazolate ligand. The $\mathrm{Re}-\mathrm{C}$ (carbonyl) and the corresponding $\mathrm{Re}-\mathrm{N}$ bond distances are about the same as those reported for other diimine systems [Re$(\mathrm{CO})_{3}($ diimine $\left.) \mathrm{L}\right], \mathrm{L}=$ amine or amide..$^{24}$ More specifically, the axial $\mathrm{Re}-\mathrm{N}$ (btpz) bond distance (2.222(5) $\AA$ ) was found to be marginally longer than the other two $\mathrm{Re}-\mathrm{N}$ distances of the phenanthroline ligand (2.184(4) and 2.192(5) $⿱$ ). The axial $\mathrm{Re}-\mathrm{N}(\mathrm{btpz})$ bond distance is within the extremes defined by the complex $\left[\operatorname{Re}(\mathrm{CO})_{3}(\right.$ phen $)$ (anilide)] containing an anilide ligand $(\mathrm{PhNH})$ with $\mathrm{Re}-\mathrm{N}=2.112(4) \AA$ and the ionic complex $\left[\operatorname{Re}(\mathrm{CO})_{3}(\right.$ phen)(aniline) $][\mathrm{OTf}]$ which contained a neutral aniline ligand with $\mathrm{Re}-\mathrm{N}=2.250$ (3) $\AA$. The observed distance suggests that the bonding behavior of the negatively charged pyrazolato $\mathrm{N}$-atom is akin to the neutral aniline due to the strong electron withdrawing effect imposed by the $\mathrm{CF}_{3}$ functional groups. In good agreement with this finding, the $\mathrm{Re}-\mathrm{C}$ distance of the carbonyl ligand trans to the pyrazolate ligand $(1.897(7) \AA)$ is very close to the corresponding $\mathrm{Re}-\mathrm{C}$ distances for other two $\mathrm{CO}$ ligands (1.897(7) and 1.905(5) $\AA$ ), demonstrating a rare situation where there is almost no trans influence between the anionic pyrazolato ligand and the neutral phenanthroline group.

UV-Vis Spectra. Figure 2 shows UV-vis spectra of the pyrazolato complexes $\mathbf{1}$ and $\mathbf{2}$ in dichloromethane. For these metal complexes, the dominant absorption bands in the 250$300 \mathrm{~nm}$ region were assigned to the intraligand $\pi \rightarrow \pi^{*}$ transitions. These assignments were based on the absorption spectra of the free ligands as well as those of the closely related metal complexes. ${ }^{25}$ On the other hand, the low energy broad bands in the near UV region $\left(\lambda_{\max }\right.$ about $361 \mathrm{~nm}$ for 1 and $\lambda_{\max }$ about $353 \mathrm{~nm}$ for 2 ) that extends to approximately $450 \mathrm{~nm}$ are attributed to the metal to ligand charge-transfer

(24) (a) Connick, W. B.; Di Bilio, A. J.; Hill, M. G.; Winkler, J. R.; Gray, H. B. Inorg. Chim. Acta 1995, 240, 169. (b) Hevia, E.; Perez, J.; Riera, V.; Miguel, D. Organometallics 2002, 21, 1966.

(25) Yam, V. W.-W.; Lau, V. C.-Y.; Wu, L.-X. J. Chem. Soc., Dalton Trans. 1998, 1461 and references therein.
$\mathrm{d}_{\pi}(\mathrm{Re}) \rightarrow \pi^{*}(\mathrm{~N}-\mathrm{N})$ transitions. Similar spectral patterns were observed when the spectra were recorded in acetonitrile solution, of which the data are listed in Table 3. It is clear that all MLCT absorption bands of complexes $\mathbf{1}$ and $\mathbf{2}$ are similar to those observed in the related $\operatorname{Re}(\mathrm{I})$ carbonyl complexes, and all exhibited a small blue shift compared to their parent complexes, $\left[\operatorname{Re}(\mathrm{CO})_{3}(\mathrm{bpy}) \mathrm{Br}\right]\left(\lambda_{\max }=378 \mathrm{~nm}\right)$ and $\left[\operatorname{Re}(\mathrm{CO})_{3}(\mathrm{phen}) \mathrm{Br}\right]\left(\lambda_{\max }=370 \mathrm{~nm}\right){ }^{26} \mathrm{We}$ believe that the electron density on the $\operatorname{Re}(\mathrm{I})$ metal can be partially suppressed by the replacement of bromide ion with the btpz nitrogen donor ligand. Thus, the btpz ligand can lead to a slight decrease in $d_{\pi}(R e)$ orbital energy, giving a slightly high-energy MLCT transition. By changing the solvent polarity, a 10-15 $\mathrm{nm}$ blue shift in the MLCT band was observed on going from nonpolar $\mathrm{CH}_{2} \mathrm{Cl}_{2}$ to polar $\mathrm{CH}_{3} \mathrm{CN}$. On the other hand, the maxima of the higher energy absorption bands were found to be insensitive to the solvent polarity as well as the concentration, confirming that they are mainly derived from the intraligand $\pi \rightarrow \pi^{*}$ transitions where no separation of charge is expected.

Emission Spectra. Luminescence experiments were conducted at room temperature from solution samples in $\mathrm{CH}_{2}$ $\mathrm{Cl}_{2}$ or acetonitrile or from solid thin film samples. As indicated in Figure 2, broad and structureless emission bands with $\lambda_{\max }=571 \mathrm{~nm}$ and $\lambda_{\max }=568 \mathrm{~nm}$ were observed for complexes $\mathbf{1}$ and $\mathbf{2}$ in deaerated $\mathrm{CH}_{2} \mathrm{Cl}_{2}$ solution upon excitation at $\lambda=366 \mathrm{~nm}$. These emission bands are then assigned as metal-to-ligand charge-transfer phosphorescent transitions $\left({ }^{3} \mathrm{MLCT}\right)$, on the basis of literature assignment of analogous $\operatorname{Re}(\mathrm{I})$ metal complexes and our experimental observation. . $^{15,23,25}$ For comparison, their parent halide complexes $\left[\operatorname{Re}(\mathrm{CO})_{3}(\mathrm{bpy}) \mathrm{Br}\right]$ and $\left[\operatorname{Re}(\mathrm{CO})_{3}(\right.$ phen $\left.) \mathrm{Br}\right]$ show strong ${ }^{3} \mathrm{MLCT}$ emission bands in the range $620-640 \mathrm{~nm}$ both in $\mathrm{CH}_{2} \mathrm{Cl}_{2}$ and $\mathrm{CH}_{3} \mathrm{CN}$ solutions. ${ }^{26}$ The blue shift of emission maximum on the replacement of bromide by btpz is consistent with the properties of their absorption spectra discussed in the previous section. No variation of the emission maximum $\lambda_{\max }$ was observed by changing solvent from $\mathrm{CH}_{2} \mathrm{Cl}_{2}$ to $\mathrm{CH}_{3} \mathrm{CN}$, and by variation of the relative concentration. On the other hand, the $\operatorname{Re}(\mathrm{I})$ metal complexes 1 and $\mathbf{2}$ exhibited a strong phosphorescent emission with $\lambda_{\max }$ $=525$ and $544 \mathrm{~nm}$ as solid-state samples, compared with the yellow-orange emission of $\mathbf{1}\left(\lambda_{\max }=571 \mathrm{~nm}\right)$ and $\mathbf{2}\left(\lambda_{\max }\right.$ $=568 \mathrm{~nm}$ ) observed in solution, showing the rigidochromic effect that was first proposed by Wrighton and co-workers. ${ }^{27}$ Similar rigidiochromism has been reported in the related Re(I) diimine system by measuring the photoluminescence in a frozen glass at $77 \mathrm{~K} .^{28}$ The emission band of complex $\mathbf{1}$ in anhydrous ethanol at $77 \mathrm{~K}$ remains as broad and structureless with the emission maximum exhibiting a further blue shift to $\sim 510 \mathrm{~nm}$, which is a characteristic feature of MLCT emission.

(26) (a) Kutal, C.; Weber, M. A.; Ferraudi, G.; Geiger, D. Organometallics 1985, 4, 2161. (b) Riklin, M.; Dat, T.; Bu, X.; Laverman, L. E.; Ford, P. C. J. Chem. Soc., Dalton Trans. 2001, 1813.

(27) Wrighton, M. S.; Morse, D. L. J. Am. Chem. Soc. 1974, 96, 998.

(28) (a) Stufkens, D. J. Comments Inorg. Chem. 1992, 13, 359. (b) Yam, V. W.-W. Chem. Commun. 2001, 789. 
Table 3. UV-Vis Spectral Data in $\mathrm{CH}_{2} \mathrm{Cl}_{2}$ and $\mathrm{CH}_{3} \mathrm{CN}$

\begin{tabular}{|c|c|c|c|c|c|c|c|}
\hline & \multirow[b]{2}{*}{ medium } & \multirow[b]{2}{*}{$\begin{array}{l}\operatorname{abs}^{a}\left[\lambda / \mathrm{nm}\left(\epsilon \times 10^{3}\right.\right. \\
\left.\left.\text { lit. } \mathrm{mol}^{-1} \mathrm{~cm}^{-1}\right)\right]\end{array}$} & \multicolumn{3}{|c|}{ emission } & \multicolumn{2}{|c|}{ electrochemistry $\left(E_{1 / 2} \text { in } \mathrm{V}\right)^{b}$} \\
\hline & & & $\lambda_{\max }(\mathrm{nm})$ & $\Phi$ (air) & $\Phi$ (degassed) & $\operatorname{oxidn}(\Delta E / \mathrm{mV})$ & $\operatorname{redn}(\Delta E / \mathrm{mV})$ \\
\hline 1 & $\mathrm{CH}_{2} \mathrm{Cl}_{2}$ & $\begin{array}{c}361(4.0), 319(\mathrm{sh})(10.6), \\
291(18.7), 234(30.0)\end{array}$ & 571 & $1.9 \times 10^{-3}$ & $3.3 \times 10^{-3}$ & +1.55 & $-1.47(109)$ \\
\hline 1 & $\mathrm{CH}_{3} \mathrm{CN}$ & $\begin{array}{l}345(3.5), 317(11.3), 301(\mathrm{sh})(12.0) \\
\quad 281(13.1), 235(23.7)\end{array}$ & 573 & $2.8 \times 10^{-3}$ & $3.8 \times 10^{-3}$ & $+1.47(80)$ & $-1.37(100)$ \\
\hline 1 & solid & & 525 & & & & \\
\hline 2 & $\mathrm{CH}_{2} \mathrm{Cl}_{2}$ & $353(4.1), 276(s h)(23.2), 262(24.7)$ & 568 & $4.1 \times 10^{-3}$ & $2.2 \times 10^{-2}$ & +1.56 & $-1.44(104)$ \\
\hline 2 & $\mathrm{CH}_{3} \mathrm{CN}$ & $341(s h)(4.9), 274(26.8), 259(25.7)$ & 571 & $1.1 \times 10^{-2}$ & $4.1 \times 10^{-2}$ & $+1.53(119)$ & $-1.29(96)$ \\
\hline 2 & solid & & 544 & & & & \\
\hline
\end{tabular}

${ }^{a}$ sh denotes shoulder. ${ }^{b} E_{1 / 2}=\left(E_{\mathrm{pa}}+E_{\mathrm{pc}}\right) / 2 ; E_{\mathrm{pa}}=$ anodic peak potential, $E_{\mathrm{pc}}=$ cathodic peak potential; $\Delta E=\left|E_{\mathrm{pa}}-E_{\mathrm{pc}}\right|$ in mV. Metal-based oxidation is irreversible in $\mathrm{CH}_{2} \mathrm{Cl}_{2}$.

Excitation at either the $\pi-\pi^{*}$ absorption band $(\sim 280 \mathrm{~nm})$ or the MLCT absorption band ( $\sim 350 \mathrm{~nm})$ leads to the same structureless MLCT emission at both room temperature and $77 \mathrm{~K}$, except for the concurrent change in the emission intensities. This observation indicates that the potential surface crossing from the higher $\pi-\pi^{*}$ state to the lower MLCT state is quite efficient, and the major contribution of the observed emission is from the MLCT state. ${ }^{16,29}$ Moreover, it is also known that heavy metal atom would provide efficient spin-orbit coupling so as to facilitate intersystem crossing and thereby enhance the orbital crossing in the singlet-triplet forbidden transition. Thus, the involvement of the $\operatorname{Re}(\mathrm{I})$ metal is critical to the observation of strong phosphorescence.

The excitation spectra, measured by monitoring the respective emission $\lambda_{\max }$, match perfectly with the respective absorption spectra of both complexes $\mathbf{1}$ and $\mathbf{2}$, giving an indication that the final and major emitting state originates from the same electronic excited state. It is noticed that the broad and low-energy MLCT band in the absorption spectra has now partially resolved into two bands in the scanning excitation spectrum (Figure 2), namely the ${ }^{1}$ MLCT and ${ }^{3}$ MLCT states, at 345 and $390 \mathrm{~nm}$, and 350 and $390 \mathrm{~nm}$ for complexes $\mathbf{1}$ and $\mathbf{2}$, respectively. The strong spin-orbit coupling imposed by the Re atom allows the upper excited state to relax into the spin forbidden ${ }^{3}$ MLCT state and then emit light from this state. Notice that the excitation spectrum also has an absorption maximum at the $\pi \rightarrow \pi^{*}$ transition, supporting our previous statement that the potential surface crossing from the $\pi \rightarrow \pi^{*}$ state to the MLCT state is quite efficient.

The identity of the photoluminescent emissions is further revealed by the measurement of excited-state lifetimes, which lie on the order of microseconds and are typical for the emissions from the ${ }^{3}$ MLCT and the intraligand ${ }^{3} \pi \rightarrow \pi^{*}$ states. As indicated in Figure 3, the photoluminescence of bpy complex 1 is composed of two exponential decays with lifetimes of $1.56 \mu \mathrm{s}(92 \%)$ and $0.51 \mu \mathrm{s}(8 \%)$. The long-lived, major component is thus assigned to the emission from the ${ }^{3}$ MLCT state, and the minor shorter-lived component is assigned to originate from the $\pi \rightarrow \pi^{*}$ state. In general, if there is no potential surface crossing from the higher bpy $\pi$

(29) Sacksteder, L.; Zipp, A. P.; Brown, E. A.; Streich. J.; Demas, J. N.; DeGraff, B. A. Inorg. Chem. 1990, 29, 4335.

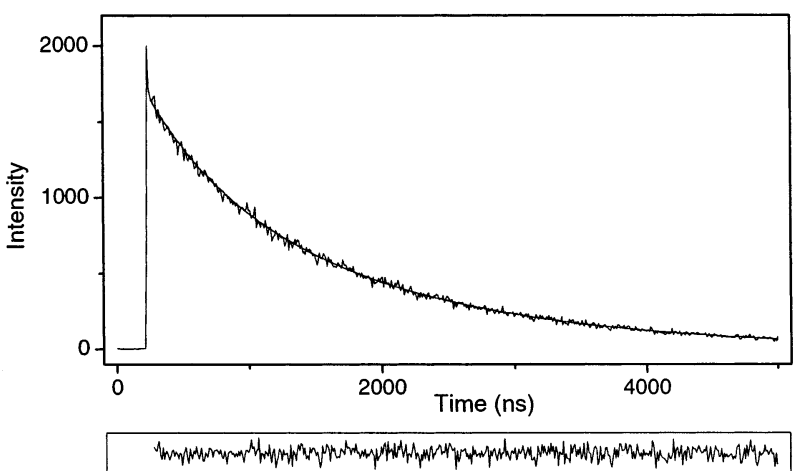

Figure 3. Photoluminescence lifetime decay measurement of the solid thin film of complex $\mathbf{1}$. The excitation wavelength is $366 \mathrm{~nm}$, and the emission is monitored at $525 \mathrm{~nm}$.

$\rightarrow \pi^{*}$ state to the lower MLCT state, one can expect, on the basis of the energy gap law, a longer decay lifetime from the $\pi \rightarrow \pi^{*}$ state than the lower MLCT state. ${ }^{29}$ Moreover, the potential surface crossing from the $\pi \rightarrow \pi^{*}$ state to the MLCT state in the present system is quite efficient; therefore, the assignment of the short-lived, minor decay component to originate from the $\pi \rightarrow \pi^{*}$ state should be reasonable. Complex 2 also exhibits a biexponential decay pattern with lifetimes of $1.39 \mu \mathrm{s}(87 \%)$ and $0.44 \mu \mathrm{s}(13 \%)$. The $\operatorname{Re}(\mathrm{I})$ carbonyl complexes that show multiexponential decay kinetics are known, confirming the existence of two light-emission excited states with comparable energies..$^{30}$ Finally, luminescence quantum yields of these complexes in air-saturated and deaerated solution were also measured (see Table 3), and the magnitude of the quantum yields are somewhat similar to those of the related rhenium(I) diimine complexes. ${ }^{15,16}$ Notice that complex 2 shows 4 times higher luminescence quantum yield in a deaerated solution than a solution prepared without applying repeated freeze-pumpthaw cycles. Such an $\mathrm{O}_{2}$-sensitive luminescence quantum yield in solution can be considered as a characteristic feature of the phosphorescent emission.

Electrochemistry. Cyclic voltammetric experiments were carried out in $\mathrm{CH}_{3} \mathrm{CN}$ and $\mathrm{CH}_{2} \mathrm{Cl}_{2}$ solutions of $0.1 \mathrm{M} \mathrm{TBAH}$ at a scan rate of $100 \mathrm{mV} / \mathrm{s}$. The redox potentials obtained from cyclic voltammograms are presented in Table 3. Both metal complexes show reversible metal-centered oxidation

(30) (a) Shaw, J. R.; Schmehl, R. H. J. Am. Chem. Soc. 1991, 113, 389. (b) Wallace, L; Rillema, D. P. Inorg. Chem. 1993, 32, 3836. (c) Striplin, D. R.; Crossby, G. A. Coord. Chem. Rev. 2001, 211, 163. 
Ranjan et al.

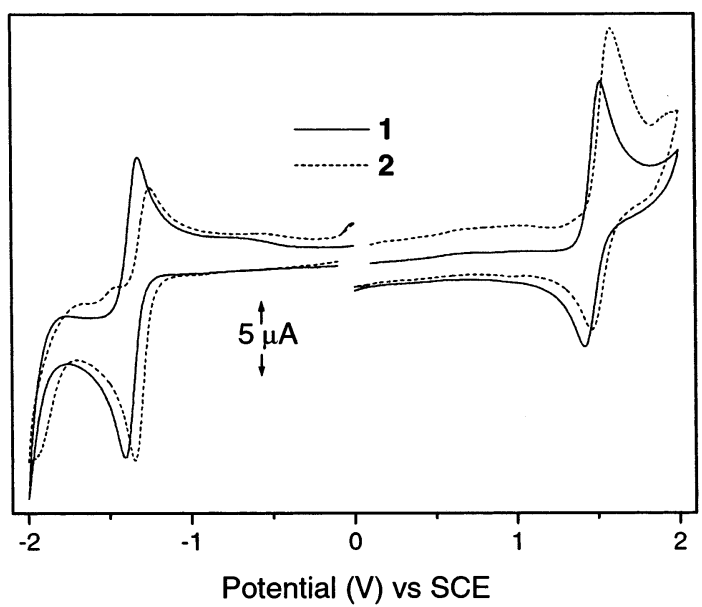

Figure 4. Cyclic voltammograms of complexes 1 and 2 measured in $\mathrm{CH}_{3-}$ $\mathrm{CN}$ (vs SCE) at a scan rate of $100 \mathrm{mV} / \mathrm{sec}$. A Pt metal and a Pt mesh were used as the working electrode and the counter electrode, respectively. TBAH was taken as supporting electrolyte.

and ligand-based reduction in $\mathrm{CH}_{3} \mathrm{CN}$ solution, which are consistent with the redox behavior of $\operatorname{Re}(\mathrm{I})$ diimine complexes reported in the literature..$^{25,31}$ The reduction cycle, however, behaves irreversibly upon changing solvent to $\mathrm{CH}_{2-}$ $\mathrm{Cl}_{2}$. As indicated in Figure 4, complex 1 shows two reversible couples at +1.47 and $-1.37 \mathrm{~V}$ vs SCE in $\mathrm{CH}_{3} \mathrm{CN}$ which attributed to the independent one electron processes $\operatorname{Re}(\mathrm{I})$ $\rightarrow \operatorname{Re}(\mathrm{II})$ and (bpy) $\rightarrow\left(\right.$ bpy $\left.^{{ }^{-}}\right)$, respectively. It is notable that the oxidation potential shows a much larger difference with respect to the parent complex $\left[\operatorname{Re}(\mathrm{CO})_{3}(\mathrm{bpy}) \mathrm{Br}\right]\left(E_{1 / 2}\right.$ $=+1.36 \mathrm{~V} ;-1.32 \mathrm{~V}$ vs SCE). It is believed that the poor $\sigma$-donating and good $\pi$-accepting ability of btpz ligand renders the $\operatorname{Re}(\mathrm{I})$ metal center impoverished in electron density and, hence, decreases its oxidation potential.

Complex 2 shows a similar redox behavior. The small difference in the oxidation potentials of the $\operatorname{Re}(\mathrm{I})-\operatorname{Re}(\mathrm{II})$ couples between $\mathbf{1}$ and $\mathbf{2}$ shows little relationship to the donor/acceptor capability of phenanthroline vs the bipyridine ligand. The lack of obvious correlation indicates that the basicity of the diimine ligand has minimal effect on the stability of the metal $d_{\pi}$ level. Moreover, the energy levels of the highest occupied molecular orbital (HOMO) and lowest unoccupied molecular orbital (LUMO) are calculated using the following formula: $E_{\mathrm{HOMO}}=-4.74-E_{\mathrm{pa}}$ (onset) $\left(-4.74 \mathrm{~V}\right.$ for SCE with respect to zero vacuum level ${ }^{32}$ and $E_{\mathrm{pa}}($ onset $)=+1.28 \mathrm{~V}$ for $\mathbf{1}$ and $+1.34 \mathrm{~V}$ for $\mathbf{2}$ ) and $E_{\mathrm{LUMO}}$ $=1240 / \lambda_{\mathrm{abs}}-E_{\mathrm{HOMO}}$. These calculations give the HOMO and LUMO energy levels to be -6.02 and $-3.23 \mathrm{eV}$ and -6.07 and $-3.28 \mathrm{eV}$ for complexes $\mathbf{1}$ and $\mathbf{2}$, respectively.

OLED Devices. A variety of devices have been constructed where complexes $\mathbf{1}$ and $\mathbf{2}$ were employed as the emitting materials. In general, the use of these complexes as a pure emitting layer in a three layer ITO/HTL/dye/ETL/ $\mathrm{Mg}:$ Ag structure resulted in poor performance and unstable devices. Better results were achieved with complexes $\mathbf{1}$ and

(31) Kaim, W.; Kramer, H. E. A; Vogler, C.; Rieker, J. J. Organomet. Chem. 1989, 367, 107.

(32) Bard, A. J.; Faulkner, L. R. Electrochemical Methods Fundamental and Applications; Wiley: New York, 1980
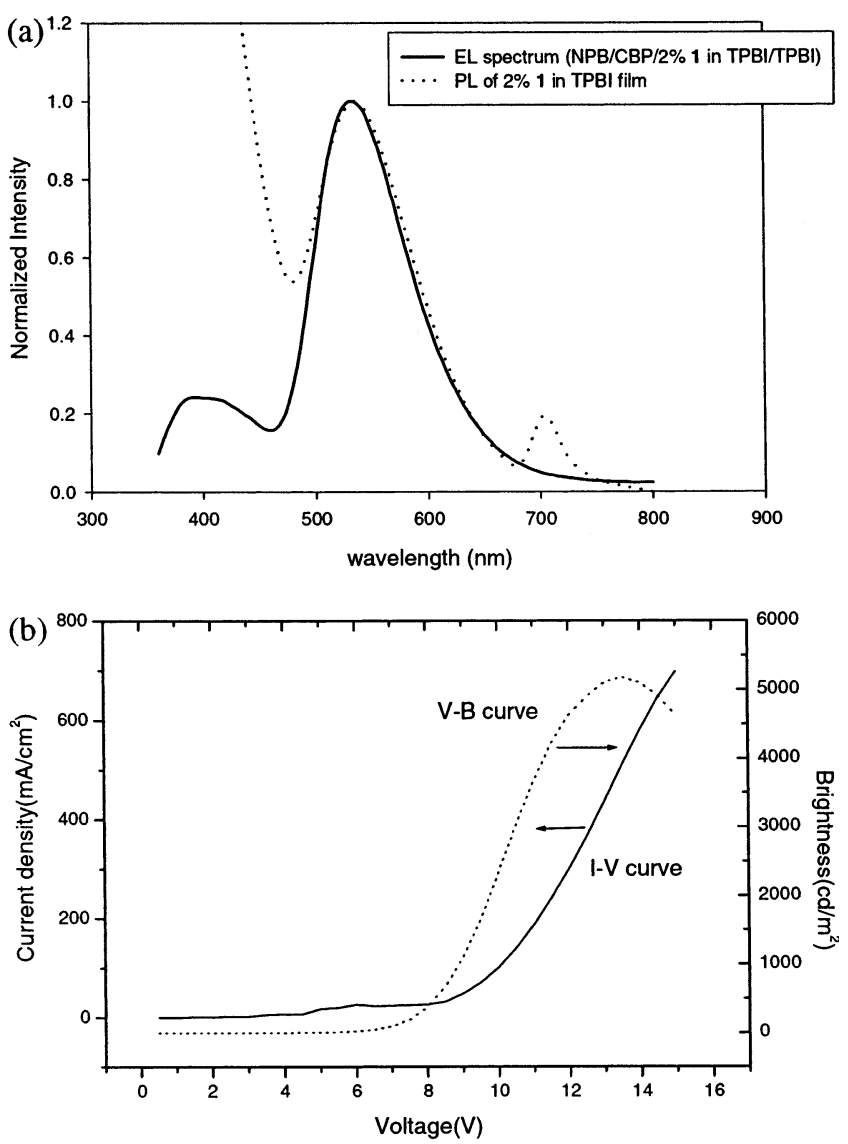

Figure 5. (a) EL spectrum of the device ITO/NPB $(40 \mathrm{~nm}) / \mathrm{CBP}(20 \mathrm{~nm}) /$ TPBI:2\%(1)(20 nm)/TPBI $(20 \mathrm{~nm}) / \mathrm{Mg}: \mathrm{Ag}$. (b) The $I-V-L$ characteristics of the device.

2 and phosphorescent dopants in host materials, 4,4'dicarbazolyl-1'1-biphenyl (CBP) and 2,2',2"'-(1,3,5-benzenetriyl)tris[1-phenyl-1H-benzimidazole] (TBPI), ${ }^{33}$ which exhibit photoluminescent emission in the region $380-400 \mathrm{~nm}$. These host emission bands significantly overlap with absorption bands of complexes $\mathbf{1}$ and $\mathbf{2}$, thus ensuring the efficient Förster/Dexter type of energy transfer. Complexes $\mathbf{1}$ and $\mathbf{2}$ behaved similarly in terms of electroluminescent properties, and thus, only the results for $\mathbf{1}$ are presented here.

Figure 5a shows the EL spectrum for a device with the configuration ITO/NPB(40 nm)/CBP(20 nm)/TPBI:2\%(1)$(20 \mathrm{~nm}) / \mathrm{TPBI}(20 \mathrm{~nm}) / \mathrm{Mg}$ :Ag. The configuration was chosen as it was shown before ${ }^{34}$ that the electron-transporting TPBI layer behaves as a hole-blocking layer in a typical two-layer TPB/TPBI device. To generate TPBI excitons for energy transfer, recombination occurring in the TPBI layer is necessary. The CBP layer, with a HOMO level $(5.5 \mathrm{eV})$ lying between that of NPB $(5.2 \mathrm{eV})$ and TPBI $(6.2 \mathrm{eV})$, paves the way for holes to transport from NPB into the TPBI layer where charge recombination occurs. The $\lambda_{\max }$ at $532 \mathrm{~nm}$ recorded at a low voltage of $6 \mathrm{~V}$ nicely overlaps with the PL spectrum of similarly doped TPBI:2\%(1) film and close to the PL spectrum recorded for the solid film of $\mathbf{1}$,

(33) Adachi, C.; Baldo, M. A.; Forrest, S. R.; Lamansky, S.; Thompson, M. E.; Kwong, R. C. Appl. Phys. Lett. 2001, 78, 1622.

(34) (a) Tao, Y. T.; Balasubramaniam, E.; Danel, A.; Tomasik, P. Appl. Phys. Lett. 2000, 77, 933. (b) Tao, Y. T.; Balasubramaniam, E. Tomasik, P.; Danel, A. Chem. Mater. 2000, 12, 2788. 

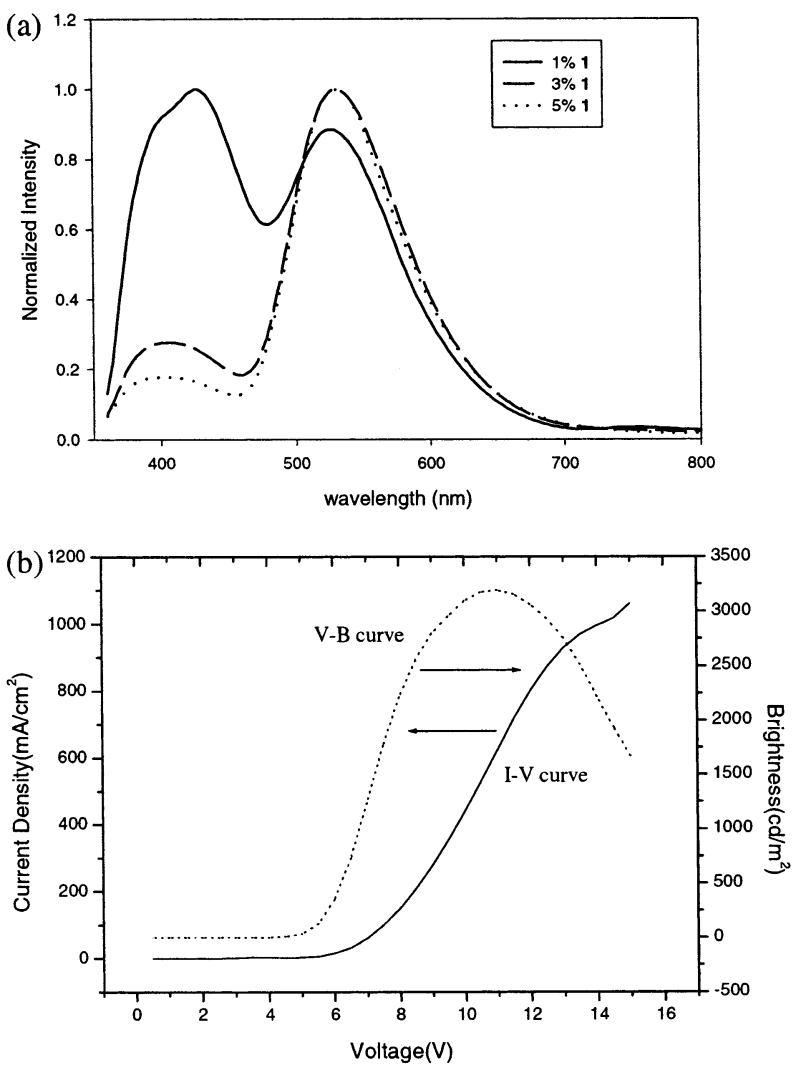

Figure 6. (a) EL spectrum of the device ITO/NPB(40 nm)/CBP:(1)(x\%)$(20 \mathrm{~nm}) / \mathrm{TBPI}(20 \mathrm{~nm}) / \mathrm{Mg}$ :Ag. (b) The $I-V-L$ characteristics for the device with $5 \% 1$ as dopant.

suggesting that the emission came from complex 1. A shoulder at $\sim 390 \mathrm{~nm}$ was assigned as the emission from CBP. ${ }^{33}$ The device nevertheless showed a strong voltage dependence. With increasing voltage, the contribution from $\mathrm{CBP}$ at $\sim 390 \mathrm{~nm}$ and NPB at $\sim 445 \mathrm{~nm}$ increased, and the color shifted to the blue. The shift is attributed to the shifting of the recombination region at higher field, where more electrons are injected and passed to the HTL layer. Figure $5 \mathrm{~b}$ presents the device characteristics. At a driving current of $100 \mathrm{~mA}$, the device gave a luminance of $\sim 2300 \mathrm{~cd} / \mathrm{m}^{2}$, an external quantum efficiency of $0.82 \%$, and a power efficiency of $0.72 \mathrm{~lm} / \mathrm{W}$.

Devices with complex 1 doped in the CBP layer in a configuration of ITO/NPB(40 nm)/CBP:(1) $(x \%)(20 \mathrm{~nm}) /$ TBPI $(20 \mathrm{~nm}) / \mathrm{Mg}: \mathrm{Ag}$ were also fabricated. Figure $6 \mathrm{a}$ shows the EL spectra as a function of the doping concentration. An emission $\lambda_{\max }$ at $530 \mathrm{~nm}$ was assigned as the emission at $\sim 390-450 \mathrm{~nm}$ with decreasing concentration of the dopant, presumably due to incomplete energy transfer. At 5\% dopant concentration, where the contribution from the host is very small, a green emission (CIE coordinates of $0.32,0.52$ ) with a maximum luminance of $\sim 3200 \mathrm{~cd} / \mathrm{m}^{2}$ at $11 \mathrm{~V}$ was achieved. At a driving current of $100 \mathrm{~mA}$, the device exhibited a luminance of $1800 \mathrm{~cd} / \mathrm{m}^{2}$, an external quantum efficiency of $0.6 \%$, a power efficiency of $0.74 \mathrm{~lm} / \mathrm{W}$, and a current efficiency of $1.76 \mathrm{~cd} / \mathrm{A}$, respectively.

Generally speaking, the maximum luminescence for the present devices behaves slightly better than that of the EL devices prepared from the co-deposition of phenol-pyridine beryllium and $\operatorname{Re}(\mathrm{I})$ complex $\operatorname{Re}(\mathrm{CO})_{3}\left(\mathrm{Bu} u^{t} b p y\right) C l$, which showed an EL emission peak at $535 \mathrm{~nm}$ and luminescence of $2182 \mathrm{~cd} / \mathrm{m}^{2}$ with the rhenium metal complex being doped at a similar concentration level of $5 \% .{ }^{13 \mathrm{~b}}$ When the concentration of the $\operatorname{Re}(\mathrm{CO})_{3}\left(\mathrm{Bu}^{t} \mathrm{bpy}\right) \mathrm{Cl}$ complex is increased to $50 \%$, the device gives a maximum efficiency of $1.6 \mathrm{~lm} / \mathrm{W}$ and brightness of $6450 \mathrm{~cd} / \mathrm{m}^{2}$. This is somewhat in contrast to our finding that the higher dopant concentration $(\geq 7 \%)$ would substantially reduce the power efficiency. Moreover, the EL emission of our devices were blue-shifted compared with those of the devices prepared from functionalized Re(I) complexes $\operatorname{Re}(\mathrm{CO})_{3}(\mathrm{~L}) \mathrm{Cl}$, where $\mathrm{L}=2$-(1-ethylbenzimidazol-2-yl)pyridine or a bipyridine ligand that contained both hole transport triphenylamine and electron transport aromatic 1,3,4-oxadiazole pendants, but a substantially low luminance of $\leq 350 \mathrm{~cd} / \mathrm{m}^{2}$ was observed. ${ }^{13 \mathrm{c}, \mathrm{e}}$

\section{Conclusion}

Rhenium complexes $\mathbf{1}$ and $\mathbf{2}$ have been successfully synthesized and have shown good volatility as they can be sublimed without any notable decomposition below $150{ }^{\circ} \mathrm{C}$. These properties allow them to be used in OLED devices via vacuum sublimation. Excited state lifetime measurements confirm that the electronically excited Re complexes 1 and 2 can display phosphorescent emission with triplet excited state lifetimes ${ }^{3} \tau$ of 0.51 and $1.56 \mu$ s for $\mathbf{1}$, and 0.44 and $1.39 \mu$ s for $\mathbf{2}$, respectively. The bright green phosphorescent emission was attributed to the emissions from both the ${ }^{3}$ MLCT and the intraligand ${ }^{3} \pi \rightarrow \pi^{*}$ excited states. Green electroluminescence from complex 1 could be obtained when it was used as a dopant in the CBP and NPB based OLED devices. Although the device design has not yet been optimized, the current results have shown that OLED devices based on complex $\mathbf{1}$ have the most promising performance among various rhenium metal complexes reported in the literature. Efforts are being taken to further optimize the performances of OLED devices based on rhenium complexes 1 and 2.

Acknowledgment. We thank the National Science Council and Ministry of Education, Taiwan, Republic of China for funding (Grant NSC 91-2113-M-007-047 and MOE 89FA04-AA).

Supporting Information Available: X-ray crystallographic file (CIF) for complex 2 . This material is available free of charge via the Internet at http://pubs.acs.org.

IC0259181 